\title{
Aplikasi Pupuk Organik Cair Berbahan Baku Urin Ternak Terhadap Pertumbuhan Tanaman Pakcoy (Brassica rapa L.)
}

\section{AGRISINTECH}

Journal of Agribusiness and Agrotechnology

Vol. 2, No. 1 (2021)

\section{(Application of Liquid Organic Fertilizer Material From Livestock Urine on Pakcoy (Brassica rapa L.) Plant \\ Growth)}

\begin{abstract}
Liquid organic fertilizer made from urine from livestock is an alternative to environmentally friendly fertilizers that can increase pakcoy production and growth. Based on this, researchers are interested in conducting research to determine the effect of liquid organic fertilizer made from livestock urine on the growth of pakcoy (Brassica rapa L.). The experiment was carried out with five treatments using a completely randomized design (CRD), namely the application of liquid organic fertilizer from goat urine, cow urine and rabbit urine, chemical fertilizer $A B$ Mix as a comparison and without fertilization (control). Observations were made on plant height, number of leaves, dry weight and wet weight of harvest. Data were analyzed using SPSS software and further tested with Duncan Multiple Range Test (DMRT). The results of the study were that in all liquid organic fertilizers there was an increase in the content of $P$ elements, a decrease in K elements and $\mathrm{pH}$ after fermentation. 70/Permentan/SR.140/10/2011 concerning organic fertilizers, biological fertilizers, and soil enhancers. Liquid organic fertilizer made from livestock urine is able to increase the number of leaves and plant height of pakcoy which is significantly different from chemical fertilizers. The application of goat urine liquid organic fertilizer resulted in the same dry weight and wet weight of pakcoy harvest as chemical fertilizers.
\end{abstract}

Keywords: organic fertilizer, pakcoy, cow, goat, rabbit.

\begin{abstract}
ABSTRAK
Pupuk organik bentuk cair berbahan urin dari ternak adalah salah satu alternatif pupuk ramah lingkungan yang dapat meningkatkan produksi dan pertumbuhan pakcoy. Berdasarkan hal tersebut, peneliti terdorong melaksanakan kajian dengan tujuan mengetahui dampak pemberian pupuk organik cair berbahan urin ternak terhadap perkembangan tumbuhan pakcoy (Brassica rapa L.). Percobaan lima perlakuan memakai Rancangan Acak Lengkap (RAL) yang merupakan pemberian tipe pupuk organik cair hasil ternak urin kambing, urin sapi dan urin kelinci, pupuk kimia AB Mix sebagai pembanding dan tanpa pemupukan (kontrol). Pengamatan dilakukan terhadap tinggi tanaman, kuantitas daun, berat kering dan berat basah panen. Data dianalisis menggunakan software SPSS serta diuji Duncan Multiple Range Test (DMRT). Hasil kajian yaitu pada semua pupuk organik cair terjadi peningkatan kandungan unsur $\mathrm{P}$, penurunan unsur $\mathrm{K}$ dan $\mathrm{pH}$ setelah difermentasi $\mathrm{pH}$ berkisar 6,85-8,45 dan sesuai dengan peraturan Menteri Pertanian No. 70/Permentan/SR.140/10/2011 tentang pupuk organik, pupuk hayati, dan pembenah tanah. Pupuk organik cair berbahan urin ternak mampu meningkatkan jumlah daun dan tinggi tanaman pakcoy yang secara sig nifikan berbeda dibandingkan pupuk kimia. Aplikasi pupuk organik cair urin kambing menghasilkan berat kering dan berat basah panen pakcoy yang serupa dengan pupuk kimia.
\end{abstract}

Kata Kunci : pupuk organik, pakcoy, sapi, kambing, kelinci. 


\section{PENDAHULUAN}

Tanaman Pakcoy (Brassica rapa L.) merupakan ragam lalap yang bernilai ekonomis, disenangi warga Indonesia karena kesegaran, tekstur renyah, dan rasa yang enak (Nurhasanah 2015). Produksi sawi pada tahun 2018 mencapai 1.503.446 ton dan produktivitas 6,59 ton per hektar, namun produksinya masih lebih rendah dibandingkan wortel (BPS, 2019). Produksi pakcoy rendah diakibatkan karena menurunnya mutu tanah baik unsur kimia, biologi, dan unsur fisik tanah, pemberian pupuk anorganik secara kontinu, serta bahan organik tanah yang hilang (Nurhasanah, 2015).

Kualitas tanah dapat diperbaiki dengan cara pemberian pupuk organik. Pupuk organik menjadikan keadaan struktur, serta fisik tanah, dapat menaikkan kekuatan untuk menahan air, serta memperbaiki sifat biologi tanah dan kimia tanah (Firmansyah, 2011). Pupuk hayati/organik memiliki keunggulan yaitu ramah lingkungan, murah dan mudah didapat serta dapat di buat sendiri (Jasmidi et al. 2018). Pupuk organik lebih ramah lingkungan dibandingkan pupuk kimia, karena pupuk kimia beresiko mengotori dan merugikan lingkungan khususnya tanah, jika pupuk kimia dipakai secara berlebih.

Salah satu jenis pupuk organik yaitu pupuk organik cair. Pupuk cair memiliki unsur-unsur yang mudah terurai sehingga tanaman mudah menyerap unsur tersebut. Pada pupuk organik bentuk cair, terdapat mikroba yang bermanfaat untuk tanaman seperti mikroba fotosintesis, mikroba asam laktat, jamur fermentasi (Aspergillus sp), Saccharomyces sp atau ragi, Actinomycetes. Mikroorganisme tersebut bermanfaat untuk tanaman, karena kandungan nutrisi yang dihasilkan untuk tanah dapat meningkatkan produksi tanaman dan mencegah penyakit pada tanaman (Indriani, 2005). Oleh karena itu, perlu adanya penelitian tentang aplikasi pupuk organik bentuk cair berbahan baku urin ternak dan pengaruhnya terhadap perkembangan tanaman pakcoy (Brassica rapa L.).

\section{METODE PENELITIAN}

\section{Lokasi dan Lama Penelitian}

Kajian dimulai dari bulan Juli sampai Agustus 2020, berlokasi di Kelompok Rumah Departemen Agama, Kelurahan Bambu Apus, Kecamatan Pamulang, Tanggerang Selatan dan Laboratorium Kimia Universitas Nusa Bangsa Bogor.

\section{Bahan dan Alat}

Penelitian menggunakan bahan yaitu urin kambing, urin sapi, urin kelinci, dekomposer EM-4, tetes tebu, pupuk kimia AB-MIX untuk pembanding dan tanaman pakcoy. Peralatan yang digunakan adalah derigen ukuran 4 liter, polibag ukuran $20 \times 25 \mathrm{~cm}$, hand sprayer ukuran 1 liter, timbangan, gelas ukur, alat tulis seperti penggaris dan kamera.

\section{Rancangan percobaan}

Rancangan percobaan yang digunakan adalah Rancangan Acak Lengkap (RAL) dengan lima percobaan bahan pupuk organik cair. Penelitian dilakukan untuk melihat pengaruh penggunaan 3 jenis pupuk organik cair berbahan urin kambing, urin sapi dan urin kelinci dan 2 perlakuan lain sebagai pembanding. Dosis perlakuan sebagai berikut, E0 : kontrol (tanpa pupuk), E1 : EM-4 $10 \mathrm{ml}$, tetes tebu $15 \mathrm{ml} /$ liter urin kambing, E2 : EM-4 $10 \mathrm{ml}$, tetes tebu $15 \mathrm{ml} /$ liter urin sapi, E3 : EM-4 $10 \mathrm{ml}$, tetes tebu 15 $\mathrm{ml} /$ liter urin kelinci dan E4 : pupuk kimia cair.

\section{Metode}

1. Menyusun pembuatan pupuk organik bentuk cair

Pupuk organik cair dibuat di Laboratorium Kimia Universitas Nusa Bangsa. Urin ternak dari para peternak di Bogor, dituangkan kedalam ember yang berbeda 
masing-masing sebanyak 4 liter. Kemudian tambahkan EM-4 sebanyak $10 \mathrm{ml} /$ liter urin dan tetes tebu $15 \mathrm{ml}$ /liter urin. Aduk hingga rata dan difermentasi selama 14 hari. Urin ternak yang belum difermentasi dan yang sudah difermentasi dianalisis unsur $\mathrm{P}, \mathrm{N}, \mathrm{K}$ dan $\mathrm{pH}$.

2. Penanaman tanaman pakcoy

Penanaman tanaman pakcoy, dimulai dengan persiapan media. Media yang akan ditanam adalah pupuk kandang, campuran sekam dan tanah, perpaduan tanah $0,5 \mathrm{~kg}$ : sekam $0,166 \mathrm{~kg}$ : pupuk kandang 0,166 kg per polibag. Media tanam dicampur dan diaduk hingga merata, selanjutnya dimasukkan ke dalam polibag. Benih pakcoy disemai, setelah tumbuh dan memiliki 3 daun, kemudian dipindahkan kedalam polibag yang telah dipersiapkan.

3. Aplikasi pupuk cair

Pemberian pupuk cair urin ternak dilakukan setiap 4 hari sekali. Pupuk organik diaplikasikan pada tanaman pakcoy dengan cara disemprotkan ke daun. Dosis penyemprotan $10 \mathrm{ml} /$ liter air pada umur 1-12 hari setelah tanam (hst), dosis $20 \mathrm{ml} /$ liter air pada umur 12-24 hst, dan dosis $30 \mathrm{ml} /$ liter air pada umur 24-40 hst.
4. Pengamatan

Pengamatan pertumbuhan tanaman pakcoy dilakukan pada tinggi tanaman, kuantitas daun, berat kering dan berat basah. Pengukuran awal dilakukan sejak tanaman berumur 8 hst dengan interval pengamatan setiap 8 hari sekali. Daun yang dihitung adalah jumlah sudah terbuka sempurna. Selanjutnya, mengukur tinggi tanaman dari batang bawah (atas tanah) sampai pucuk.

Bobot basah diamati saat panen yaitu tanaman berumur 40 hst. Pengamatan dilakukan dengan cara tanaman dicabut dari polibag, akar dan batang dicuci dengan air bersih mengalir, diamkan beberapa menit dan timbang bobotnya. Bobot kering diukur dengan cara tanaman yang sudah ditimbang bobot basah, kemudian oven dengan lama waktu 24 jam, suhu $80^{\circ} \mathrm{C}$ sampai menghasilkan berat konstan (Salisbury \& Ross, 1995).

\section{HASIL DAN PEMBAHASAN}

Pupuk organik bentuk cair yang sudah jadi, kemudian dianalisis kandungan hara NPK dengan hasil sebagaimana Tabel 1.

Tabel 1. Kandungan unsur N, K, KA pada urin ternak dan tanah

\begin{tabular}{|c|c|c|c|c|c|c|}
\hline \multicolumn{2}{|c|}{ Pupuk } & \multirow{2}{*}{$\frac{\mathbf{p H}}{8,59}$} & \multirow{2}{*}{$\frac{\mathbf{N}(\%)}{-}$} & \multirow{2}{*}{$\frac{\mathbf{P}(\mathbf{p p m})}{1.166,89}$} & \multirow{2}{*}{$\frac{\mathbf{K}(\boldsymbol{\%})}{0,44}$} & \multirow{2}{*}{ KA (\%) } \\
\hline Urin kambing & $\begin{array}{l}\text { sebelum } \\
\text { fermentasi }\end{array}$ & & & & & \\
\hline & $\begin{array}{l}\text { setelah } \\
\text { fermentasi }\end{array}$ & 8,45 & $0,89^{\text {a) }}$ & $1.288,61$ & 0,38 & - \\
\hline \multirow[t]{2}{*}{ Urin sapi } & $\begin{array}{l}\text { sebelum } \\
\text { fermentasi }\end{array}$ & 8,42 & - & 925,71 & 0,26 & - \\
\hline & $\begin{array}{l}\text { setelah } \\
\text { fermentasi }\end{array}$ & 7.14 & $1,00^{\mathrm{b})}$ & 968,54 & 0,26 & - \\
\hline \multirow[t]{2}{*}{ Urin kelinci } & $\begin{array}{l}\text { sebelum } \\
\text { fermentasi }\end{array}$ & 8.32 & - & 792,73 & 0,14 & - \\
\hline & $\begin{array}{l}\text { setelah } \\
\text { fermentasi }\end{array}$ & 6.85 & $2,72^{c)}$ & 808,50 & 0,08 & - \\
\hline Tanah & & 7.75 & - & 619.23 & 1,00 & 3,75 \\
\hline
\end{tabular}

Analisis dilakukan dilaboratorium kimia Universitas Nusa Bangsa Bogor 2020

Ket : a). Londra, 2008 b). Sutedjo, 2010 c). Nurrohman, 2014 
Hasil analisis tingkat keasaman $(\mathrm{pH})$ urin ternak setelah difermentasi lebih rendah dari sebelum difermentasi, dengan kisaran $\mathrm{pH} 6,85-8,45$. Kisaran $\mathrm{pH}$ yang terukur sudah memenuhi persyaratan Peraturan Menteri Pertanian No.70/Permentan/SR.140/10/2011

(Kementan, 2011). Kegiatan bakteri Lactobacillus sp dalam memecah bahan dalam substrat menjadi asam organik seperti asam laktat, dapat menyebabkan terjadinya penurunan $\mathrm{pH}$ (Amanillah 2011).

Hasil analisis diperoleh kandungan hara $P$ meningkat pada urin ternak yang difermentasi. Hal ini diduga penambahan EM-4, dapat meningkatkan jumlah bakteri Lactobacillus sp sebagai dekomposer bahan organik. Peningkatan jumlah mikroba ini memacu proses metabolisme dalam menghasilkan mineral fospat. Menurut Amanillah (2011), aktivitas Lactobacillus sp mengubah glukosa pada urin ternak menjadi asam laktat akan meningkatkan kadar fosfor. Lingkungan menjadi lebih asam karena asam laktat meningkat, dan mikroorganisme tersebut menghasilkan fosfat yang tergabung menjadi rantai panjang larut dalam asam organik.

Berbeda halnya dengan kandungan kalium (K) yang menurun setelah difermentasi. Penurunan tersebut diduga karena perlakuan selama proses fermentasi (pembalikan) terlalu lama, sehingga unsur kalium berkurang. Unsur $\mathrm{N}$ tidak dapat dilakukan langsung, namun beberapa hasil penelitian kandungan $\mathrm{N}$ paling tinggi terdapat pada urin kelinci $2,72 \%$ (Nurrohman, 2014), kandungan $\mathrm{N}$ pada urin sapi $1,00 \%$ (Sutedjo, 2010) dan kandungan $\mathrm{N}$ pada urin kambing 0,89\% (Londra, 2008).

\section{Pengujian pada tanaman Pakcoy}

Jumlah daun

Hasil penelitian pada laju pertumbuhan jumlah daun tanaman pakcoy, menunjukkan ada pengaruh perlakuan pupuk organik bentuk cair urin ternak terhadap variabel jumlah daun tanaman pakcoy mulai 8 hst hingga $32 \mathrm{hst}$ dan berbeda nyata dengan perlakuan lainnya (Tabel 2).

Tabel 2. Rata-rata laju pertumbuhan kuantitas daun tanaman pakcoy

\begin{tabular}{lccccc}
\hline & \multicolumn{5}{c}{ Jumlah Daun } \\
\cline { 2 - 5 } Perlakuan & $\mathbf{8}$ hari & $\mathbf{1 6}$ hari & $\mathbf{2 4}$ hari & $\mathbf{3 2}$ hari & $\mathbf{4 0}$ hari \\
\hline E0 (kontrol) & $5.41^{\mathrm{ab}}$ & $6.66^{\mathrm{ab}}$ & $9.41^{\mathrm{ab}}$ & $12.03^{\mathrm{ab}}$ & 15.00 \\
E1 (urin kambing) & $5.33^{\mathrm{ab}}$ & $6.66^{\mathrm{ab}}$ & $9.08^{\mathrm{ab}}$ & $12.33^{\mathrm{ab}}$ & 16.00 \\
E2 (urin sapi) & $5.66^{\mathrm{ab}}$ & $7.33^{\mathrm{a}}$ & $10.00^{\mathrm{a}}$ & $12.66^{\mathrm{ab}}$ & 16.75 \\
E3 (urin kelinci) & $5.83^{\mathrm{a}}$ & $7.33^{\mathrm{a}}$ & $9.91^{\mathrm{a}}$ & $13.16^{\mathrm{a}}$ & 16.75 \\
E4 (pupuk kimia) & $5.16^{\mathrm{b}}$ & $6.25^{\mathrm{b}}$ & $8.50^{\mathrm{b}}$ & $11.41^{\mathrm{b}}$ & 15.00 \\
\hline
\end{tabular}

Catatan: Angka-angka yang diikuti huruf yang sama tidak berbeda nyata menurut uji DMRT taraf 5\%. 


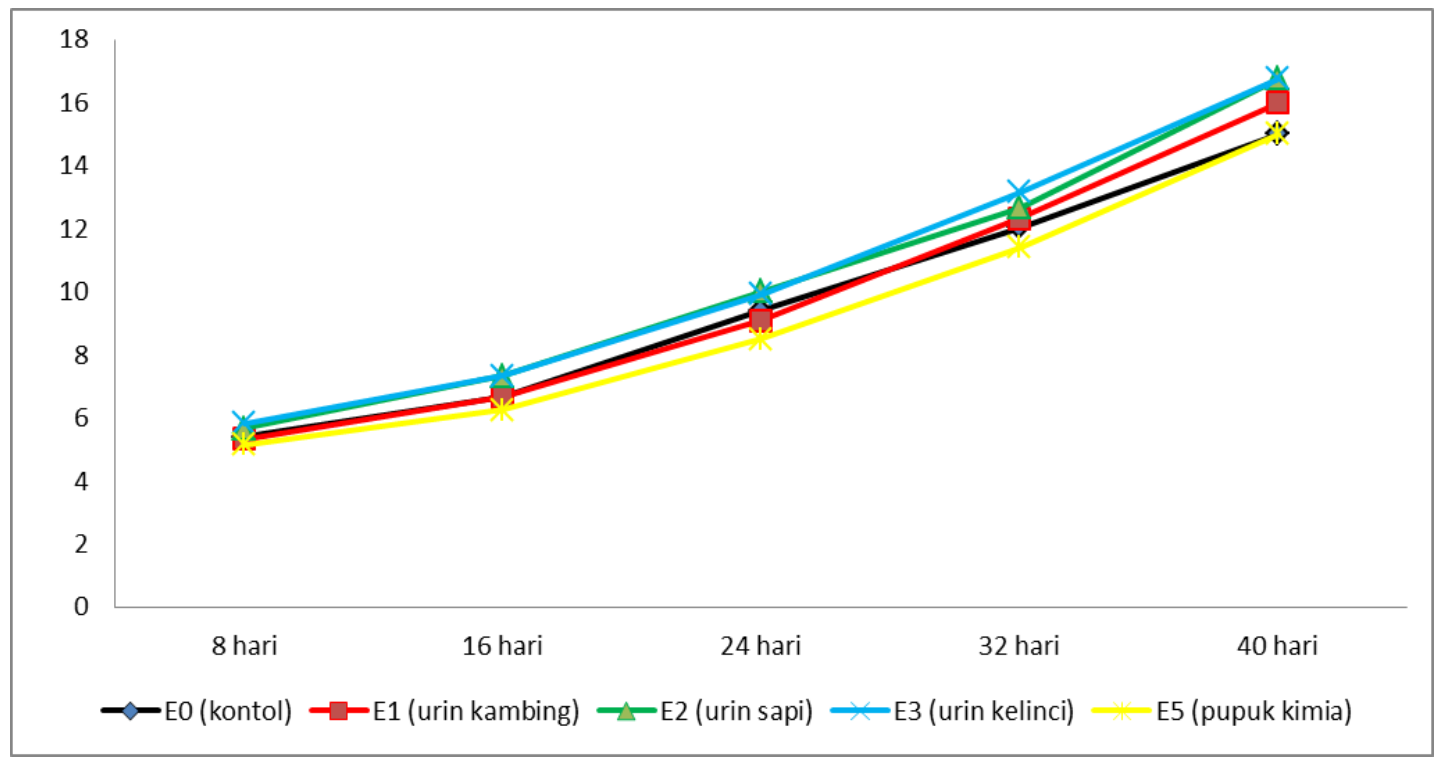

Gambar 1. Grafik laju pertumbuhan jumlah daun tanaman pakcoy

Aplikasi pupuk organik cair berbahan urin ternak kelinci (E3) menghasilkan dampak yang paling baik terhadap penambahan kuantitas daun dibandingkan perlakuan lainnya, sejak 8 hst hingga 32 hst. Pembentukan daun diduga dipengaruhi oleh unsur $\mathrm{N}$ yang terdapat dalam pupuk organik cair berbahan urin ternak kelinci (E3) yang lebih tinggi. Nitrogen diperlukan tanaman untuk meningkatkan pertambahan vegetatif tanaman, termasuk kuantitas daun (Kurniawan et al. 2017). Kualitas pertumbuhan dan hasil tanaman akan maksimal jika menggunakan nitrogen dengan dosis yang tepat (Okazaki et al. 2012).

Secara keseluruhan, bahwa perlakuan pupuk organik cair urin ternak efektif dalam meningkatkan pertumbuhan jumlah daun dibandingkan dengan perlakuan pupuk kimia. Pupuk organik bentuk cair didalamnya terkandung unsur $\mathrm{N}$, P dan K. Pembentukan daun tidak hanya dipengaruhi oleh ketersedian unsur $\mathrm{N}$ saja, tetapi dipengaruhi juga oleh unsur P dan K (Prizal dan Nurbaiti, 2017).

\section{Tinggi tanaman}

Pada laju pertumbuhan tinggi tanaman pakcoy diamati dan diperoleh hasil bahwa pemberian pupuk organik urin ternak memberikan efek terhadap tinggi tanaman pakcoy dan berbeda nyata dengan perlakuan pupuk kimia mulai umur 24 hst (Tabel 3).

Tabel 3. Rata-rata laju pertumbuhan tinggi tanaman pakcoy

\begin{tabular}{lrrrrc}
\hline \multirow{1}{*}{ Perlakuan } & \multicolumn{5}{c}{ Tinggi tanaman ( cm ) } \\
\cline { 2 - 6 } & $\mathbf{8}$ hari & $\mathbf{1 4}$ hari & $\mathbf{2 4}$ hari & $\mathbf{3 2 ~ h a r i}$ & $\mathbf{4 0 ~ h a r i}$ \\
\hline E0 ( kontrol ) & 4.01 & 5.82 & $7.65 \mathrm{a}$ & $8.00 \mathrm{ab}$ & $8.71 \mathrm{~b}$ \\
E1 ( urin kambing ) & 3.63 & 5.19 & $7.50 \mathrm{a}$ & $8.58 \mathrm{ab}$ & $10.06 \mathrm{a}$ \\
E2 ( urin sapi ) & 3.97 & 5.35 & $7.27 \mathrm{a}$ & $8.69 \mathrm{a}$ & $9.97 \mathrm{a}$ \\
E3 ( urin kelinci ) & 4.24 & 5.72 & $7.17 \mathrm{a}$ & $8.50 \mathrm{ab}$ & $9.50 \mathrm{ab}$ \\
E4 ( pupuk kimia ) & 3.15 & 4.73 & $5.99 \mathrm{~b}$ & $7.60 \mathrm{~b}$ & $8.97 \mathrm{ab}$ \\
\hline
\end{tabular}

Catatan : Angka-angka yang diikuti huruf yang sama tidak berbeda nyata menurut uji DMRT taraf 5\%. 


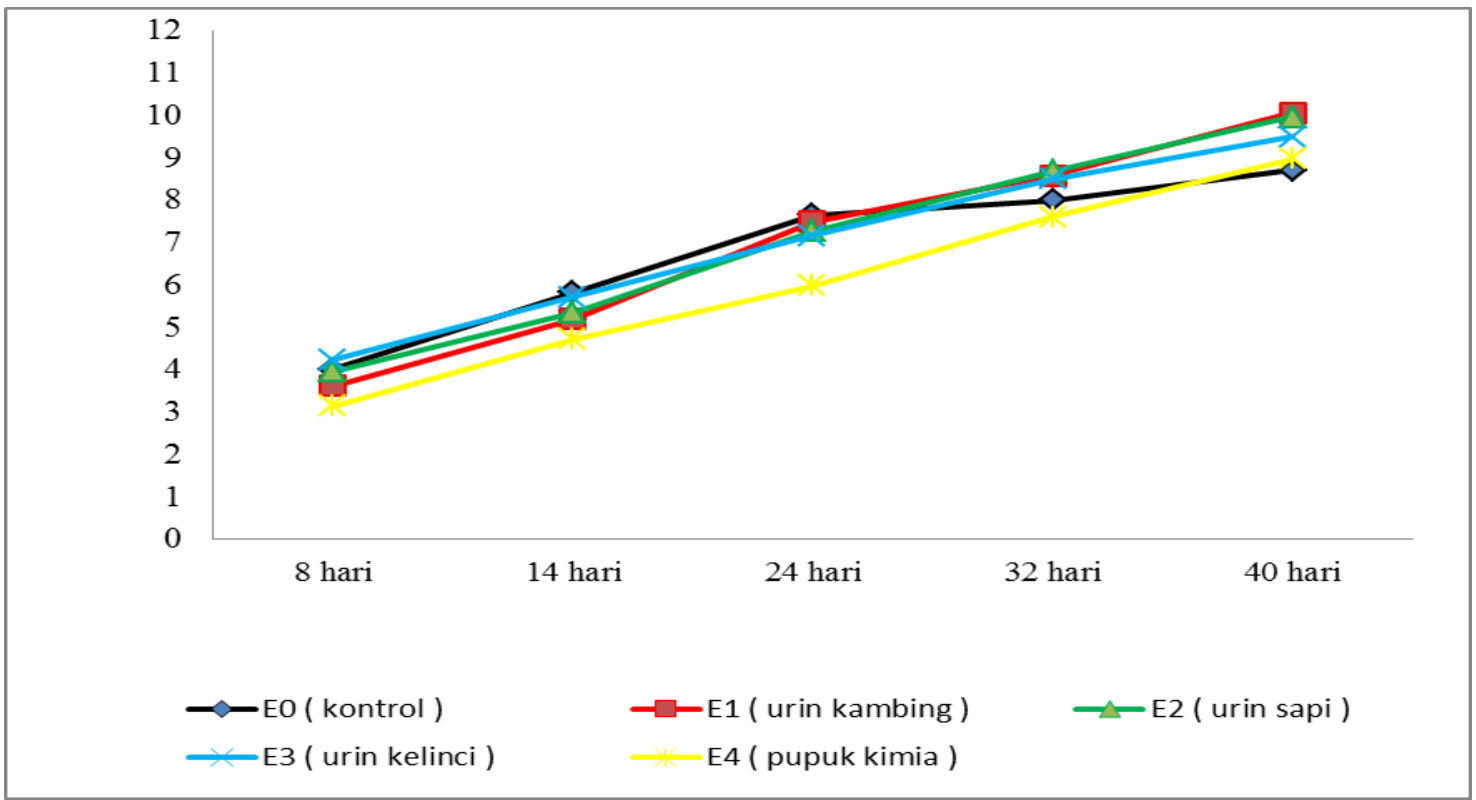

Grafik 2. Laju pertumbuhan tinggi tanaman pakcoy

Aplikasi pupuk organik cair berbahan urin ternak memberikan efek lebih baik terhadap penambahan tinggi tanaman daripada menggunakan pupuk kimia. Respon tinggi tanaman yang paling baik ditunjukkan oleh pemberian pupuk organik cair berbahan urin ternak kambing (E1) hingga umur 40 hst. Respon tersebut diduga terjadi karena unsur $\mathrm{P}$ lebih tinggi daripada pupuk organik bentuk cair lain. Unsur $\mathrm{P}$ merupakan unsur penting yang berperan dalam fotosintesis, peningkatan tinggi tanaman, dan perkembangan akar (Simanungkalit, 2006).

Respon pertumbuhan tinggi tanaman paling kecil diperoleh dari perlakuan kontrol (E0) yaitu tidak diberikan pupuk. Respon pertumbuhan tinggi tanaman yang berbeda akan dipengaruhi oleh ketersediaan dan kuantitas zat hara yang dapat diterima oleh tanaman. Aplikasi pupuk organik bentuk cair memiliki dampak yang besar dalam menambah ketersediaan unsur hara, sehingga dapat dimanfaatkan oleh tanaman pakcoy. Hal ini sesuai dengan penelitian Kurniawan dkk., bahwa hasil pertumbuhan tanaman sangat tergantung dari jenis unsur yang terkandung dalam pupuk (Kurniawan et al. 2017).

\section{Bobot basah}

Hasil pengamatan berat basah tanaman pakcoy dapat dilihat pada Tabel 4.

Tabel 4. Rata-rata hasil berat basah tanaman pakcoy

\begin{tabular}{lc}
\hline Perlakuan & Bobot basah (gram) \\
\hline E0 (kontrol) & $106.33^{\mathrm{ab}}$ \\
E1 (urin kambing) & $126.58^{\mathrm{ab}}$ \\
E2 (urin sapi) & $93.92^{\mathrm{b}}$ \\
E3 (urin kelinci) & $94.17^{\mathrm{b}}$ \\
E4 (pupuk kimia) & $136.50^{\mathrm{a}}$
\end{tabular}

Catatan: Angka-angka yang diikuti huruf sama, tidak berbeda nyata menurut uji DMRT taraf 5\%.

Berat basah pakcoy tertinggi diperoleh dari perlakuan pupuk kimia (E4) yaitu seberat 136,50 gram dan beda nyata dengan perlakuan lain. Aplikasi pupuk organik bentuk cair urin kambing (E1) menghasilkan bobot basah 126,58 gram, sama saja dengan perlakuan kontrol (E0), namun berbeda nyata dengan perlakuan pupuk organik cair urin sapi (E2) dan urin kelinci (E3). Hal ini diduga pada pupuk 
AB-Mix terkandung unsur hara makro dan mikro yang tersedia dan dapat dimanfaatkan oleh tanaman pakcoy, sehingga dapat mendorong proses pertumbuhan tanaman pakcoy. Bagian kecil/mikro dari unsur hara tersebut berperan dalam menambah hasil, kualitas panen, dan membuat efisien dalam penggunaan pupuk makronutrien (Malakouti, 2008). Tanaman akan tumbuh dan produksi secara optimum jika elemen hara makro dan mikro sesuai dengan tanaman butuhkan.

\section{Bobot kering}

Aplikasi pupuk organik cair menghasilkan berat kering tanaman pakcoy yang berbeda-beda (Tabel 5).

Tabel 5. Rata-rata hasil bobot kering tanaman pakcoy dengan pemberian POC dari urin ternak yang berbeda selama 40 hari setelah tanam.

\begin{tabular}{lc}
\hline Perlakuan & Bobot kering (gram) \\
\hline E0 (kontrol) & $8.58^{\mathrm{ab}}$ \\
E1 (urin kambing) & $10.08^{\mathrm{a}}$ \\
E2 (urin sapi) & $7.75^{\mathrm{b}}$ \\
E3 (urin kelinci) & $8.25^{\mathrm{ab}}$ \\
E4 (pupuk kimia) & $10.50^{\mathrm{a}}$
\end{tabular}

Catatan: Angka-angka yang diikuti huruf sama tidak berbeda nyata menurut uji DMRT taraf 5\%.

Aplikasi pupuk organik cair urin kambing (E1) menghasilkan bobot kering paling tinggi yaitu 10,08 gram dibandingkan perlakuan pupuk organik bentuk cair lain. Pupuk organik cair urin kambing (E1) memproduksi bobot kering tanaman pakcoy yang tidak berbeda nyata dengan perlakuan pupuk kimia (E4) berdasarkan uji DMRT pada taraf 5\%. Perbedaan bobot kering yang dihasilkan diduga karena mengandung unsur hara berbeda dari setiap jenis pupuk yang dipakai. Masing-masing unsur hara punya peran yang berbeda dalam membantu pertumbuhan dan produksi pakcoy. Produksi tanaman dipengaruhi oleh banyak atau sedikit suatu unsur hara yang tersedia, diserap, dan digunakan tanaman (Kurniawan et al. 2017).

\section{SIMPULAN}

Semua pupuk organik cair berbahan urin ternak setelah difermentasi terjadi peningkatan kandungan unsur $\mathrm{P}$, penurunan unsur $\mathrm{K}$ dan $\mathrm{pH}$. $\mathrm{pH}$ yang terukur berkisar $6,85-8,45$ dan sudah sesuai dengan persyaratan pupuk organik cair atas dasar Permentan No 70/Permentan/SR.140/10/2011. Pupuk organik bentuk cair berbahan urin ternak mampu meningkatkan jumlah daun dan tinggi tanaman pakcoy yang secara signifikan berbeda dibandingkan pupuk kimia. Aplikasi pupuk organik cair urin kambing menghasilkan berat basah dan berat kering panen tanaman pakcoy yang sama dengan pupuk kimia.

\section{DAFTAR PUSTAKA}

Amanillah, Z. (2011). Pengaruh konsentrasi EM-4 pada fermentasi urine sapi terhadap konsentrasi $N, P$, dan K. (Skripsi). Malang: Fakultas Matematika dan Ilmu Pengetahuan Alam, Universitas Brawijaya Malang.

BPS. (2019). Statistik Tanaman Sayuran dan Buah-Buahan Semusim Indonesia 2018. In S. S. Hortikultura (Ed.). BPS RI. Diunduh 11 Agustus 2020 dari https://www.bps.go.id/publication/2 $\underline{019 / 10 / 07 /}$

9c5dede09c805bc38302ea1c/statisti k-tanaman-sayuran-dan-buahbuahan-semusim-indonesia2018.html

Firmansyah, MA. (2011). Peraturan Tentang Pupuk, Klasifikasi Pupuk Alternatif Dan Peranan Pupuk Organik Dalam Peningkatan 
Produksi Pertanian. Makalah disampaikan pada Apresiasi Pengembangan Pupuk Organik, di Dinas Pertanian dan Peternakan Provinsi Kalimantan Tengah, Palangka Raya. Palangka Raya: Dinas Pertanian dan Peternakan Provinsi Kalimantan Tengah, Palangka Raya.

Indriani, YH. (2005). Pengaruh Rasio Penggunaan Limbah Ternak dan Hijauan terhadap Kualitas Pupuk Cair. Yogyakarta: Pangan Kanisius.

Jasmidi, Zainuddin M, \& Prastowo P. (2018). Pemanfaatan Urin Sapi menjadi Pupuk Organik Cair Kelompok Tani Desa Sukadamai Timur. Jurnal Pengabdian Kepada Masyarakat. 24(1), 570-575.

Kementerian Pertanian. (2011). Peraturan Menteri Pertanian Nomor 70/Permentan/SR.140/10/2011

Tentang Pupuk Organik, Pupuk Hayati dan Pembenah Tanah. Jakarta: Kementerian Pertanian Republik Indonesia.

Kurniawan A, Islami $\mathrm{T}$, \& Koesriharti. (2017). Pengaruh Aplikasi Pupuk N dan K Terhadap Pertumbuhan dan Hasil Tanaman Pakcoy (Brassica rapa var. chinensis) Flamingo F1. Jurnal Produksi Tanaman, 5(2), 281 - 289.

Londra. (2008). Membuat Pupuk cair Bermutu dari Limbah Kambing. Warta Penelitian dan Pengembangan Pertanian Indonesia, 30(6), 5-7.

Malakouti, M. J. (2008). The Effect of Micronutrients in Ensuring Efficient Use of Macronutrients. J. For Agriculture, 32(1), 215-220.
Nurhasanah, O., (2015). Pemberian Kombinasi Pupuk Hijau Azolla pinnata Dengan Pupuk Guano Terhadap Pertumbuhan Dan Produksi Tanaman Pakcoy (Brassica chinensis L.). Universitas Riau. Jurnal Online Mahasiswa Fakultas Pertanian Universitas Riau, 2(1).

Nurrohman, M., A. Suryanto \& K. W. Puji. (2014). Penggunaan fermentasi ekstrak paitan (Tithonia diversifolia L.) dan kotoran kelinci cair sebagai sumber hara pada budidaya sawi (Brassica juncea L.) secara hidroponik rakit apung. Jurnal Produksi Tanaman, 2(8), 649-657.

Okazaki, K., T. Shinano, N. Oka \& M. Takebe. (2012). Metabolite profiling of Komatsuna (Brassica rapa L.) fieldgrown under different soil organic amendment and fertilization regimes. Journal of Soil Science and Plant Nutrition, 58(3), 696-706.

Prizal, R M dan Nurbaiti. (2017). Pengaruh Pemberian Pupuk Organik Cair Terhadap Pertumbuhan Dan Produksi Tanaman Pakcoy (Brassica rapa L.). Jurnal Online Mahasiswa Fakultas Pertanian Universitas Riau, 4(2).

Salisbury, F.B \& Ross, C.W. (1995). Fisiologi Tumbuhan, edisi ke-4. Bandung: Alih Bahasa: Diah R Lukman. Institut Teknologi Bandung.

Simanungkalit, R.D.M. \& D.A. Suriadikarta. (2006). Pupuk Organik dan Pupuk Hayati. Bogor: Balai Besar Litbang Sumberdaya Lahan Pertanian, Bogor 10 pp. 